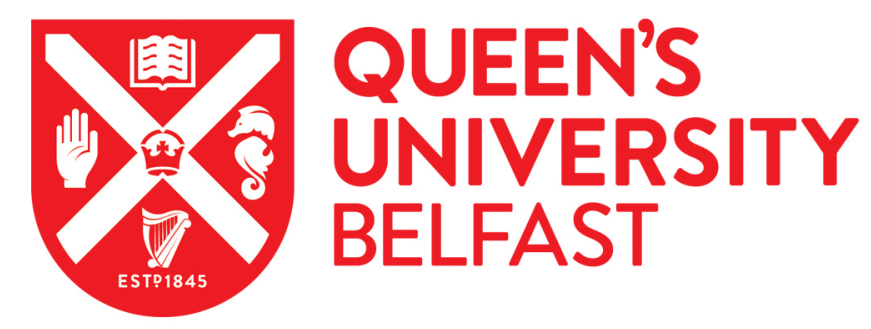

\title{
Micro-scale wear characteristics of electroless Ni-P/SiC composite coating under two different sliding conditions
}

Franco, M., Sha, W., Malinov, S., \& Liu, H. (2014). Micro-scale wear characteristics of electroless Ni-P/SiC composite coating under two different sliding conditions. Wear, 317(1-2), 254-264.

https://doi.org/10.1016/j.wear.2014.06.013

\section{Published in:}

Wear

\section{Document Version:}

Peer reviewed version

Queen's University Belfast - Research Portal:

Link to publication record in Queen's University Belfast Research Portal

\section{General rights}

Copyright for the publications made accessible via the Queen's University Belfast Research Portal is retained by the author(s) and / or other copyright owners and it is a condition of accessing these publications that users recognise and abide by the legal requirements associated with these rights.

Take down policy

The Research Portal is Queen's institutional repository that provides access to Queen's research output. Every effort has been made to ensure that content in the Research Portal does not infringe any person's rights, or applicable UK laws. If you discover content in the Research Portal that you believe breaches copyright or violates any law, please contact openaccess@qub.ac.uk. 
Micro-scale wear characteristics of electroless Ni-P/SiC composite coating under two different sliding conditions

\author{
M. Franco ${ }^{1}$, W. Sha ${ }^{1, *}$, S. Malinov ${ }^{2}$, H. Liu ${ }^{3}$ \\ ${ }^{1}$ School of Planning, Architecture and Civil Engineering, Queen's University Belfast, Belfast \\ BT7 1NN, UK \\ ${ }^{2}$ School of Mechanical and Aerospace Engineering, Queen's University Belfast, Belfast BT7 \\ $1 \mathrm{NN}, \mathrm{UK}$ \\ ${ }^{3}$ Light Industry Equipment Advanced Manufacturing and Measurement and Control \\ Technology Provincial Key Laboratory, School of Mechanical and Automotive Engineering, \\ Qilu University of Technology, Ji'nan 250100, P. R. China
}

* Corresponding author. Tel.: +4428 90974017; fax: +442890974278.

E-mail address: w.sha@qub.ac.uk (W. Sha). 


\begin{abstract}
The electroless nickel composite (ENC) with various silicon carbide contents was deposited onto aluminium alloy (LM24) substrate. The wear behaviour and the microhardness of the composite coating samples were investigated and compared with particles free and aluminium substrate samples using micro-scale abrasion tester and microhardness tester respectively. The wear scar marks and wear volume were analysed by optical microscope. The wear tracks were further studied using scanning electron microscopy (SEM). The embedded particles were found to get pressed into the matrix which helps resisting further wearing process for composite samples. However, random orientation of micro cuts and micro fallow were seen for ENC sample but more uniform wearing was observed for EN sample. The composite coating with low content of $\mathrm{SiC}$ was worn minimum. Early penetration into the substrate was seen for samples with higher SiC content. Microhardness was improved after heat treatment for all the samples containing various $\mathrm{SiC}$ content. Under dry sliding condition, inclusion of particles in the matrix did not improve the wearing resistance performance in as-deposited state. The wearing worsened as the content of the particles increased generally. However, on heat treatment, the composite coatings exhibited improved wear resistance and the best result was obtained from the one with low particle contents.
\end{abstract}

Keywords: micro-scale abrasion; metal-matrix composite; wear testing; electron microscopy; hardness; optical microscopy 


\section{Introduction}

Surface of the material has paramount importance when it comes to interaction with other surfaces during the course of applications where sliding, rubbing and scratching occur against another material under harsh conditions. Most of the engineering failure initiates from the surface of the material resulting in high cost. Several coating technologies have been developed to rectify the problems. However, each has its own limitation and feasibility issues. Metal deposition of nickel by electroless method is versatile owing to its unique properties such as uniformity on complex geometrical components, resistance to wear and corrosion and acceptable hardness for various industrial applications [1]. The hardness and wear resistance can be further augmented by reinforcing the metal matrix with fine abrasive particles such as silicon carbide $(\mathrm{SiC})$, alumina $\left(\mathrm{Al}_{2} \mathrm{O}_{3}\right)$, boron carbide $\left(\mathrm{B}_{4} \mathrm{C}\right)$, diamond etc. $[2]$.

Aluminium alloys have been increasingly attractive materials due to their light weight and good thermal conductivity with special attention on automobile application. Al-Si alloys are extensively used in automotive engine blocks replacing the traditional cast iron to reduce the weight for better fuel economy and for the environmental concern. Over the years, several coatings techniques have been developed to further replace the existing cast iron sleeve onto the aluminium cylinder bore. Since bare aluminium as such suffers from poor wear resistance and low hardness, surface coatings technology such as thermal spray coating, plasma spray coating, physical vapour deposition (PVD), plasma electrolytic oxidation, electroplating and electroless coating [3-10] have been developed to rectify the deficient properties of aluminium in the engine system.

Wear behaviour of the nickel based composite coating with different hard particles was studied by several researchers. Li [11] reported that Ni-P-SiC (having particle size of 1-5 $\mu \mathrm{m}$ ) 
deposit has higher wear resistance than Ni-P coating where the post wear track consists predominantly groove and peeling or scaling under the test condition of oil lubrication. Huang and Deng [12] studied the wear characteristics of Ni-P-SiC (particle size smaller than $3 \mu \mathrm{m}$ ) under machine oil lubricated condition and observed an improved wear resistance and also argued that the matrix must possess a good coordination with the hard particles to have good wear resistance. The synergistic effect of both $\mathrm{SiC}$ and PTFE contributing to offering better wear resistance under dry sliding condition was studied by Huang et al. [13]. Apachitei et al. [14] investigated the abrasion wear response of composite Ni-P-SiC and observed the improvement of wear resistance as compared to particle free coating. Strafellini et al. [15] observed two stages of wear action under dry sliding. During stage I, the deposit undergoes a mild abrasive wear whereas during stage II wear is severe and characterized by the brittle detachment of debris. Sarett et al. [16] found in micron and sub-micron sized particles that the incorporation level of the particles in the matrix depends on the size of the particles and not on the nature of the particles. The wear resistance properties and microhardness were improved specially on reinforcing with $\mathrm{SiC}$ when compared with nitride on testing in abrasion condition. Other investigators studied the wear and tribology characteristics of composite coating by reinforcing other hard particles such as $\mathrm{B}_{4} \mathrm{C}$ [17], diamond, $\mathrm{Al}_{2} \mathrm{O}_{3}$ [18] or combination of both lubricating and hard particles [19].

In most of the wear studies, only single wear condition was employed. The main aim of this research is to compare the wear characteristics of the nickel based composite coating in two sliding conditions, (a) abrasive slurry and (b) dry sliding by employing two different techniques, micro scale abrasion tester and unlubricated dry wear tester respectively. Previous study was reported on microstructure and phase transformation of electroless composite coating and the present work is the continuation of it with the aim to analyse systematically the in-depth wear mechanism and microscopic changes on lapped surface. 
The study using reference cast iron simulating the engine environment under lubricated condition is kept for separate work. Now the attention is on the study of the coating performance under two sliding conditions. The main comparison is between different coatings in post and pre heat treatment conditions. The wear responses from the two techniques could provide the basic information on the coating material properties.

\section{Experimental details}

\subsection{Plating}

Cast aluminium alloy LM24 (A1-8\%Si-3.5\%Cu alloy) was used as substrate with dimension $25 \mathrm{~mm} \times 30 \mathrm{~mm} \times 2 \mathrm{~mm}$, prepared by using energy discharge machining (EDM). Composite (Ni-P/SiC) was deposited with thickness of 30-35 $\mu \mathrm{m}$ by incorporating abrasive particles of silicon carbide, $\mathrm{SiC}$, in the nickel-phosphorus matrix using autocatalytic process as given in the previous article [20]. Prior to the metal deposition, the aluminium substrate underwent pre-treatment process which included zincating to enhance adhesion of the coating. All the pre-treatment process and parameter are given in Table 1. Each step is followed by de-ionised water rinsing. After the pre-treatment step, the samples were immediately transferred to the plating bath. The composite plating bath was prepared by introducing various concentrations of $\mathrm{SiC}$ particles (size 1-7 $\mu \mathrm{m}$ ) into a proprietary medium phosphorus electroless nickel base solution (NiKlad ELV 808MX, MacDermid). Thorough stirring of the bath was done using magnetic stirrer for about 30 minutes before the plating process starts in order to facilitate homogenous suspension of the particles. The process parameters and condition are given in Table 2. The samples were rotated using sample rotator along with the magnetic stirrer at the bottom to minimise sedimentation of the particles. The speeds of the sample rotator and the magnetic stirrer were chosen after several trials to obtain uniform suspension and minimum settling of the particles at the bottom. Separate surfactant was not used but unknown quantity 
of some surfactant was suspected in the proprietary solution. The effect of surfactants is kept as separate study. For increasing and decreasing of $\mathrm{pH}$ of the bath, $\sim 50 \% \mathrm{NH}_{4} \mathrm{OH}$ and $\sim 10 \%$ $\mathrm{H}_{2} \mathrm{SO}_{4}$ were used respectively. After the deposition, the composite samples were rinsed in running water and air dried for further studies.

Heat treatment was done in a furnace at atmospheric condition held for $1 \mathrm{~h}$ and subsequently cooled down to room temperature.

\subsection{Concept and procedure of micro-abrasion testing}

Micro-abrasion test is a volumetric wear testing method which is of particular interest on coated samples [21]. A wear scar is produced on the sample when sliding against it by a rotating steel ball in the presence of fine abrasive powder slurry. Rutherford and Hutchings [22] established this test method to simplify the wear loss study in terms of volume from the geometry of the wear scar. The testing was used to evaluate the wear behaviour of thin coatings but not as an exact application to cylinder liner of engine system. The wear scar geometry is the reproduction of the geometry of the steel sphere and also depends on the nature of the material of the sample. From the wear craters produced by continuous sliding on different location of the samples, the crater diameter is measured and subsequently, the volume can be deduced. The wear coefficient is calculated from the equation $[21,22]$

$$
V=\kappa S N
$$

where $\mathrm{V}$ is the volume of the material removed by wear, $\kappa$ is the wear coefficient, $\mathrm{S}$ is the sliding distance and $\mathrm{N}$ is the applied normal load.

The volume (V) of the spherical wear scar can be calculated from the crater diameter (b) or depth (h) using a steel ball with radius $\mathrm{R}$ : 


$$
\begin{aligned}
& V \approx \frac{\pi b^{4}}{64 R} \text { for } b \ll R \\
& V \approx \pi h^{2} R \text { for } h \ll R
\end{aligned}
$$

The abrasion wear test was conducted using a Plint TE66 micro-scale abrasion tester. A stainless steel ball (AISI 440-C having hardness 57-60 HRC) with diameter $25.4 \mathrm{~mm}$ was used to slide against the samples during which abrasive slurry (20 vol. \% SiC prepared using de-ionised water) was drip fed at the contact between the sample and the rotating ball. The balls are commercially available and no further heat treatment was carried out. The speed of the ball was maintained almost constant $\sim 76 \mathrm{rpm}$, for all the test durations of $400,600,900$, 1200, 1500 and 2000 ball revolutions. These revolutions corresponded to the sliding distances of 31.9, 47.9, 71.8, 95.8, 119.7 and $159.6 \mathrm{~m}$, respectively. Larger number of ball revolution was chosen to study the wear response at longer sliding distance even though the coating was worn through. The testing was done systematically for all the samples in the same way. It would not be known when wearing through happened during testing. So, the number of cycles was chosen in the same way for all the samples to test the wearing response in the wide range of sliding distances. The load for the wear testing is $0.5 \mathrm{~N}$. From the series of test results, a graph can be plotted showing wear volume as a function of sliding distance.

The wear scar diameter was measured by using a Nikon Eclipse ME600D optical microscope and the software Soft Imaging System Analysis was used to record the images for evaluating the wear characteristics. Further, the wear morphology and the behaviour were studied using scanning electron microscopy (SEM). The wear responses of the coating were compared with uncoated aluminium alloy in order to evaluate the effectiveness of the coating on this alloy. 


\subsection{Dry sliding wear testing}

The wear characteristic of the samples under unlubricated dry sliding was studied using a wear tester with a WC ball of $5 \mathrm{~mm}$ diameter as counterpart in ambient laboratory condition $\left(22{ }^{\circ} \mathrm{C}, 45 \%\right.$ relative humidity). A normal load of $20 \mathrm{~N}$ was applied with a rotational speed of $200 \mathrm{rpm}$ (with a circular track of $8 \mathrm{~mm}$ diameter). The wear track width and its morphology were examined by optical polyvar microscope (Reichert \& Jung, Leica). The wear rate is deduced as follows

$$
\text { Specific wear rate }=\frac{\text { Volume }}{(\text { load } \times \text { sliding distance })}
$$

where the wear loss of volume is calculated by the formula

$$
\text { Volume }=\frac{w t}{2} \times \pi d
$$

where $\mathrm{w}=$ track width, $\mathrm{t}=$ track depth, and $\mathrm{d}=$ circumference diameter $(5 \mathrm{~mm})$.

\subsection{Microhardness and surface roughness measurements}

Microhardness of the coated samples was measured using hardness tester, LECO M-400 with Knoop indenter. Measurements were made on cross section with load of $100 \mathrm{gf}$ at six different locations. For each sample, the microhardness result is the average of the six indentations and the error bar $( \pm)$ is the standard deviation. The diagonal of the indent marks were measured using the optical microscope mentioned earlier and the microhardness was calculated. The samples preparation included cutting, hot mounting using carbon based resin, grinding and polishing.

Rugosurf $10 \mathrm{G}$ roughness tester was employed for surface roughness measurement on pre and post coating samples with cut-off length of $0.8 \mathrm{~mm}$, following the standard ISO 4287:1997. Samples with $\mathrm{SiC}$ solution concentration of $2 \mathrm{~g} / \mathrm{l}, 6 \mathrm{~g} / \mathrm{l}$ and $18 \mathrm{~g} / \mathrm{l}$ were used. The calibration 
was done on reference sample at room temperature, prior to the measurements on the samples, keeping all the samples and instrument set on a vibration free desk. The average roughness $(\mathrm{Ra})$ is obtained from three readings measured at different locations on the samples.

\section{Results and discussion}

Fig. 1 shows the coating cross-section of the sample which is uniform and follows the same contour of the substrate. From our previously reported study [20], the typical cauliflower microstructure of the coating was observed. The inclusion of second phase particles (SiC) does not affect its original microstructure of the nickel matrix. The particles are simply enveloped by the metal matrix. The XRD patterns indicate the amorphous phase in the as deposited condition with a distinct crystalline peak corresponding to the SiC particles. Even after heat treatment at $500{ }^{\circ} \mathrm{C}$ no formation of any Ni-Si phases is observed.

\subsection{Micro-scale abrasion wear}

Following the investigation of phase transformation and microstructure, the micro-abrasion wear test is the continuation of the study on composite coated samples. It is worth to mention that the coating configuration can be hard on hard, soft on soft, hard on soft, soft on hard, equal hardness of both. In the present study, the electroless nickel composite coating on the aluminium alloy falls under hard on soft system. Fig. 2 shows the penetration depth and the corresponding wear volume as functions of sliding distance for bare aluminium substrate, electroless nickel (EN) and electroless nickel composite (ENC) coated samples. The penetration depth is calculated from the circular crater diameter (after averaging from vertical and horizontal diameters). The wearing penetration of the bare aluminium samples during the course of sliding is deeper as compared to both EN and ENC coated samples. The depth of penetration for ENC is found to be the lowest indicating its resistance to the force exerted by 
the rotating steel ball at the constant load. The error bars at sliding distances $71.8 \mathrm{~m}$ and $159.6 \mathrm{~m}$, corresponding to 900 and 2000 revolutions respectively, are based on two trials. The relatively large variation of results for bare aluminium might be due to inhomogeneity of the substrate.

The wear volume is deduced from the penetration depth considering that the bowl-shaped depression scar is the reproduction of the spherical steel ball. It can be mentioned that the ratio of the vertical and horizontal diameters of the crater mark is almost unity which confirms its circularity. The wear volume of the bare substrate is the largest for all the revolutions as compared to EN and ENC coated samples which are attributed to the intense abrasive action during the ball movement. When comparing with ENC, the wear volume is larger for EN samples. The difference in the wear volume could be due to the hardness of the material. Aluminium has the lowest hardness, which facilitates bigger material removal along the ball revolution. The increase in hardness, owing to the inclusion of the hard particles for ENC samples, assists in resisting the wearing process and hence the wear volume is the smallest for ENC samples in all the revolutions. The overall trend is the increase in wear volume on increase in the number of revolution (sliding distance) for all the samples. However, there are irregularities in the slope which might be due to the combined effect of inconsistency of slurry drips or concentration, heterogeneity of the samples, local strain arising from the adjacent/previous wearing process etc. Interestingly, for EN and ENC samples, respectively, the penetration depth and the resulting wear volume raises significantly at 900 (sliding distance $71.8 \mathrm{~m}$ ) and 1500 (sliding distance $119.7 \mathrm{~m}$ ) revolutions which correlate with the exposure of the aluminium substrate as seen in the optical images. The initiation of the penetration has reached the substrate, i.e., the coating is worn through (Fig. 3). 


\subsection{Surface morphology of worn samples}

The micrographs of the worn/lapped surface of the samples are shown in Fig. 4. The aluminium substrate shows a smooth surface (Fig. 4a). Absence of micro cuts and grooves indicates that the material is soft enough to get eroded uniformly during the wearing process. Fig. $4 \mathrm{~b}$ shows the lapped surface for EN sample in which scratches and grooves are observed parallel to the ball movement. The occurrence of micro cuts and micro fallow might be attributed to the mating between two hard surfaces. The EN samples have higher hardness than the aluminium alloy. For EN sample, the top original surface looks to be worn out. The worn surface for ENC sample is found to be different from the EN sample except the presence of ridge in the middle which could be due to the action by the clump of detached particles or debris entrained at the contact area between the steel ball and the sample surface. Initially as the ball rotation starts, some angular particles might have entered inside the material at the contact area. The loosely bound particles are easily carried away along with the rotation leaving shallow scratches while the firmly bound and deeper ones deepen the scratches and get entrained at the contact area leaving sharp and deeper grooves. Allsopp et al. [21] also observed the formation of ridge by the obstruction mechanism. However, for aluminium sample the formation of ridge or groove is not seen due to the inability to hold the embedded particles at the contact area or its vicinity by the soft material. For composite ENC samples, the wearing is not severe as shown by the shallow wear track where the original valley of the cauliflower microstructure is still visible which indicates the top surface is not completely worn out. Some debris and the detached particles are also seen in addition to the protuberance originally present as shown in Fig. $4 \mathrm{~d}$.

For larger sliding distance, which is 2000 revolutions, the morphology of the lapped surfaces of both EN and ENC look similar with less prominent longitudinal scratches with more material being worn out (Figs. $4 \mathrm{c}$ and $4 \mathrm{e}$ ). One reason may be that the number of revolutions 
overpowered the ability to resist the wear by the sample material. However, the ridge phenomenon is still observed for both the samples. Even at this stage of larger revolution number, the debris or detached particles clumped and embedded at the contact point and continued digging the material along with the ball revolution. This indicates that, at the contact area, the larger revolution number is insufficient to remove the material uniformly. The clear confirmation of the distinct parallel wear scratches of EN and ENC and the smooth surface corresponding to aluminium is shown in a single sample, i.e., containing both substrate and the coating (after the coating is worn through).

On closure observation of the lapped surface (Fig. 5a), the material looks to be randomly ploughed having sharp angular micro cuts without specific pattern for ENC sample. Several voids and marks are left which might be due to abrasive action of the slurry combined with the ball movement making the particles dislodging from its original location. However, some particles are also seen left embedded after the protuberances are worn out. The particles are pushed in during the wearing process and this might be beneficial for offering more resistance to wear for ENC sample as compared to EN sample. The lapped surface for the ENC sample is quite rougher than that of EN sample with the same number of revolution which could be due to the involvement of the second phase particle or part of the protuberance to cut or dig the surrounding matrix area when dislodging. The coating of the EN appears to be uniformly worn out which is obvious as the homogenous metal matrix without the presence of the second phase particle makes the removal of the material more even (Fig. 5b). At higher magnification, the worn morphology of bare aluminium and EN sample (within the coating) is similar, but the latter exhibits a finer microstructure. As compared to ENC sample, bare aluminium does not show micro notch or micro cuts (Fig. 5c).

For ENC sample, the EDX analysis of the pushed in material indicates the presence of Si with the highest peak. This point analysis clearly confirms that the black particle is the 
second phase particle $\mathrm{SiC}$ which is from the composite itself (Fig. 6). The pressed-in particles are exclusively from the composite and not from the slurry as such phenomenon is not observed in the lapped EN (particles free) sample which agrees with Rutherford and Hutchings [22] stating that abrasive particles do not get embedded in the worn surface. The scale bar from the micrograph can be used for rough measurement of the particle size which agrees with the size specification $(1-7 \mu \mathrm{m})$ of the second phase particles as mentioned earlier.

\subsection{Effect of SiC concentration on wear behaviour}

Fig. 7 shows the penetration depth and wear volume as functions of sliding distance for composite coated samples of various $\mathrm{SiC}$ percentages. Two stages of wearing process occur at (i) short and (ii) long sliding distances. For stage (i) the wearing process is smooth and gradual for all the samples. This implies that the material of the coating is degrading gradually and slowly on increasing the revolution of the steel ball where the wearing occurs mostly in coating material. This could be due to the homogeneity of the composite coating material which is having the same ability to resist the wear along the penetration depth. Sample B shows the minimum wear depth and volume for all the revolutions (sliding distance). For all the samples, at shorter sliding distance we could trace a trend in which higher SiC content in coating results in larger wearing volume and hence lower wear resistance. The wearing profile for low $\mathrm{SiC}$ samples remains largely unchanged but on increasing the content of $\mathrm{SiC}$ the steepness of the profile gradually increases.

Stage (ii) shows anomalies in the curves at longer sliding distance in which no particular trend of the effect of $\mathrm{SiC}$ percentages on the wear volume is observed. However, the low content SiC sample still exhibits significant reduction in wear volume. The higher wear volume for the higher content of $\mathrm{SiC}$ in the coating could be the result of more abrasive 
action giving negative effect by participating in the scratching or ploughing of the surface along with the rotating ball.

On observing the optical images of the worn surface for all the samples (Fig. 8), the craters become, generally, bigger on increasing the sliding distance or increasing the number of revolution. Interestingly, there is a trend of visibility of the substrate arising along the revolution as a function of various $\mathrm{SiC}$ content. In the crater, the outer ring is the coating which is darker in shade and the middle circle with lighter shade, present only after 1200 revolutions in sample $\mathrm{C}$ and 900 revolutions in samples $\mathrm{D}-\mathrm{F}$, is the substrate. It is obvious that the clarity of the two features is becoming better when seen with increasing number of revolutions for all the samples. However, the onset of the substrate approaching varies with each sample depending on the SiC content. Coincidentally, it is interesting to observe that the initial rise or slight change in the slope of the curves for wear volume occurs at the onset of substrate exposure after the coating is (almost) worn through. The penetration through (worn through) the coating is delayed for the samples with lower concentration of SiC. For sample $\mathrm{B}$, the substrate is just slightly visible after 1500 revolutions and it is distinctly visible after 2000 revolutions in which the coating is worn through completely (Fig. 3c). For sample C, the substrate is seen dimly at 1200 revolutions, earlier than sample B and it is clear after 1500 revolutions. The visibility of the substrate is again early for sample D with little exposure at 900 revolutions but seen completely after 1200 revolutions. For samples E and F, the coatings are worn through at 900 revolutions. The wearing action is more severe for the latter sample which clearly agrees with the larger gradient curve in the wear volume profile when compared with the former. The number of cycles required to wear through to the substrate is plotted (Fig. 9). The irregularities in the wear profile curve at longer sliding distance could be correlated with the material heterogeneity. The more anomalies are seen after reaching the substrate which may be due to the large dissimilarity in the material properties between the 
substrate and the coating. This observation agrees with the wear profile of the bare substrate which is more irregular comparatively. Overall, it can be concluded that micro-abrasion wear resistance is better for samples with low content of $\mathrm{SiC}$ as compared to those samples with higher SiC content.

\subsection{Coating thickness and wear depth analysis}

Coating thickness is calculated after measuring the small and large diameters of the wear dimple. The height of the spherical cap corresponding to the larger diameter is the penetration depth which is already discussed in previous sections, considering that the crater is the geometrical reproduction of the rotating steel ball. After subtracting the height of the smaller cap from larger cap, the coating thickness is obtained as given below

$$
\begin{aligned}
\text { Coating thickness } & =h_{s+c}-h_{s} \\
& =R-\sqrt{R^{2}-a_{s+c^{2}}}-\left(R-\sqrt{R^{2}-a_{s}^{2}}\right)
\end{aligned}
$$

where $h_{s+c}$ is the height of the bigger spherical cap or penetration depth, $h_{s}$ is the height of the smaller cap or substrate depth, $\mathrm{R}$ is the radius of the steel ball, $\mathrm{as}_{\mathrm{s}+\mathrm{c}}$ is the radius of the bigger outer ring and $a_{s}$ is the radius of the inner ring.

The thickness of the coating for samples A, B and F was calculated at different revolutions. For sample $\mathrm{A}$ (no $\mathrm{SiC}$ in coating), at 900 revolutions thickness of the coating was found to be $36 \mu \mathrm{m}$ but slightly larger values of $40 \mu \mathrm{m}$ and $42 \mu \mathrm{m}$ for revolution of 1500 and 2000 were obtained. The inconsistency of the thickness or a little higher in the values could be due to the lack of well-defined boundary of the ring and the inability of the material to reproduce the identical spherical cap of the rotating steel ball. The ring of the coating supports the ball to prevent from wearing. However, the thickness values are not significantly different from the expected coating thickness of $30-35 \mu \mathrm{m}$ measured from SEM. The thickness for sample B is 
calculated after the ball revolution of 2000 as the inner circle of exposed substrate is more visible here and the coating thickness was found to be $47 \mu \mathrm{m}$. For sample $\mathrm{F}$, the craters formed at 900, 1500 and 2000 were used for coating thickness calculation and the coating thickness was deduced to be $43 \mu \mathrm{m}, 44 \mu \mathrm{m}$ and $41 \mu \mathrm{m}$ respectively. These slight deviation from the actual coating values could be explained by the lack of clear boundary as mentioned before and also the chances of inability to obtain the perfect spherical cap due to the combined effect of inconsistency in drip feeding slurry, position of the sample, instrumental error and material heterogeneity.

On seeing the progressive depth of the wear dimple, it is worthwhile to mention that the wearing is gradual and regular when the penetration is still within the range of the coating thickness. This observation is more prominent for sample B in which the wearing is almost unchanged with the coating thickness. Once the sample coating depth is passed penetration is slightly accelerated which gives rise to more wearing and heterogeneities or irregularities in wearing process taking place that agrees with the exposure of the naked substrate as discussed earlier.

\subsection{Wear characteristics under dry sliding condition}

Table 3 shows the results of the wear testing under dry sliding condition. The wear rates for bare aluminium, particles free sample (A) and with particles samples $(\mathrm{B}, \mathrm{C}$ and $\mathrm{F})$ are tabulated both for as-deposited and heat treated states except for bare aluminium. It is seen that bare aluminium has higher wear rate as compared to the coatings which is generally correlated to hardness difference of the materials. The wear rate for bare aluminium is one or two orders of magnitude higher than that of the coatings except sample F. On comparing within the coated samples of varying $\mathrm{SiC}$ content, sample A (particles free) has the lowest wear rate, which increases on increasing the $\mathrm{SiC}$ content. Interestingly, in the heat treated 
state, the coated samples have wear rates of same order $\left(10^{-14}\right)$ and the wear resistance increases. Sample B (2 g/1 SiC) has the lowest wear rate among all the coated samples in heat treated condition. The optical micrographs in Fig. 10 show the post wearing surfaces. Bare aluminium exhibits longitudinal grooves with few excavations along the wearing direction. The pits might be due to the inability of the softer material to withstand the wearing force uniformly (Fig. 10a). The coated sample A has uniform wear relatively as shown in Fig. 10b. However, few fine narrow ditches are seen towards the periphery of the wear track. The wear mechanism is predominantly adhesive wear for the particles free sample A. For sample plated with $2 \mathrm{~g} / 1 \mathrm{SiC}$ (B), micro furrow and sharp channels are seen along the wearing direction (Fig. 10d). The formation of the sharper micro grooves and micro ditches is the evidence of the poor wear resistance of the composite samples with $\mathrm{SiC}$ particles in which the wearing action is accelerated by the synergistic role of both abrasive particles and wearing couple. The detached debris and dislodged particles are thought to contribute to severe wear action resulting in lower wear resistance. The mechanism involved in the wearing process is predominantly abrasive wear over adhesion wear. The lapped surfaces of heat treated coated samples for both particles free (A) and with particles (B) are identical with negligible micro grooves and micro cuts (see Figs. 10c and 10e). The absence of such remarkable degradation clearly indicates the improvement of wear resistance on heat treatment which agrees with the decreased wear rate as mentioned earlier. One reason might be the hardened matrix that enables to hold the particles without loosening debris or dislodgement to suppress further severe wearing action. In addition to the microscopic changes at post heat treatment, the formation of oxide film on the active nickel surface as $\mathrm{NiO}$ helps to provide protection and lubrication to reduce friction and hence increase wear resistance [23, 24]. 


\subsection{Microhardness}

Microhardness of the heat treated ENC samples for various SiC concentration is shown in

Fig. 11. Improvement in microhardness on heat treatment is observed for all the composite samples as compared to the untreated ones irrespective of the amount of SiC. The linearity of microhardness as a function of SiC content is not statistically significant. However a gradual increase is observed up to $6 \mathrm{~g} / 1 \mathrm{SiC}$ and then the hardness remained almost constant.

Obviously, the ENC samples have higher microhardness than the EN (particles free) both in heat-treated and as-deposited conditions. The microhardness for as-deposited samples is extracted from our previous reported work [20] to make the comparison clearer. The improvement of the microhardness on annealing is reported by many authors and it is due to the formation of hardened intermetallic $\mathrm{Ni}_{3} \mathrm{P}$ which accompanies the grain growth and volumetric shrinkage. Besides the formation of $\mathrm{Ni}_{3} \mathrm{P}$, the existence of high internal stress as observed in typical XRD pattern for heat treated EN samples could be the reason for the increase in microhardness. This internal stresses could be the result of the distortion caused by the non-equilibrium locations of the nickel and phosphorus atoms [25].

\subsection{Roughness as a function of SiC concentration}

Roughness is an important parameter for the surface texture affecting the wear characteristics. The surface roughness measurement was made before and after the plating process to logically identify the effect of the ENC coating prepared on the same substrate as the original roughness of the cast Al-Si substrate is high. There is decrease in the roughness of the samples at post coating $\left(\mathrm{R}_{\mathrm{a}}=3.7,3.8,3.95 \mu \mathrm{m}\right.$ for samples $\mathrm{B}, \mathrm{C}, \mathrm{F}$, respectively)

which is indicated by lower $R_{a}$ values as compared to those before the plating $\left(R_{a}=4.3,4.4\right.$, $4.5 \mu \mathrm{m}$ for samples B, C, F, respectively). On increasing the SiC content for ENC samples, i.e., comparing the sample $\mathrm{C}$ with $\mathrm{B}$, the surface roughness remains almost constant. Further 
increasing up to $18 \mathrm{~g} / \mathrm{l}$, for sample $\mathrm{F}$, no major changes in the Ra value is observed. However, on visual inspection, the surface of higher $\mathrm{SiC}$ content looks foggy and rough as compared with samples with lower SiC content.

\section{Conclusion}

Electroless composite coating with $\mathrm{SiC}$ as second phase particles was prepared. For ENC samples, random micro cut and micro fallows were observed after abrasion wear with some dislodged notches left behind by the particles. Some particles were seen to get pressed in during ball revolution. The pressed in particles were exclusively from the composite and not from the abrasive slurry. At smaller numbers of revolution, the samples were worn gently and getting thinner slowly indicating the homogeneity of the wearing in the same coating material. However, once the coating thickness is reached, anomalies in the trend were observed. The worn morphologies of EN and ENC both show similar wear mark or track at larger ball revolution numbers but differ at smaller revolution numbers with more longitudinal grooves for the former and less material being removed for the latter. Coating thickness calculation from the wear dimple was satisfactory, though slightly larger thickness values could be due to several factors such as inconsistency in drip feeding slurry, position of the sample, instrumental error and material heterogeneity, resulting to produce an imperfect spherical cap.

Under dry sliding condition, inclusion of particles in the matrix does not improve the wear resistance performance in as-deposited state. The wearing is more severe as the content of the particles increases generally. However, on heat treatment, the reinforced composite coating exhibits improved wear resistance and the best result is obtained from the one with less particles. 
Microhardness was found to be improved on heat treatment when compared with asdeposited condition, irrespective of the $\mathrm{SiC}$ content. It increases up to certain $\mathrm{SiC}$ concentration and above which there is no large change. ENC samples have higher microhardness than EN (particles free) samples. Surface roughness of the ENC samples was reduced post coating. However, there is no significant difference with the change in SiC concentration. Thus, electroless nickel composite coating surpasses both EN and aluminium samples with respect to abrasive micro wear response and microhardness values.

\section{Acknowledgements}

The authors would like to acknowledge the financial support as the Queen's University International Studentship for the $\mathrm{PhD}$ project. Special thanks to Dr. Mark Russell, Mr. Stephen McFarland and Mr. Jim Knox and his team of our University for their help in carrying out the experiments. Dr. R. Rajendra of B.S. Abdur Rahman University, Chennai is also gratefully appreciated.

\section{References}

[1] D. Baudrand, Electroless nickel plating, ASM Handbook (Vol. 5): Surface Engineering, ASM International, Materials Park, OH, 1994, pp. 290-310.

[2] Jothi Sudagar, Jianshe Lian, Wei Sha, Electroless nickel, alloy, composite and nano coatings - A critical review, J. Alloy. Compd., 571 (2013) 183-204.

[3] Seiya Kunioka, Tadashi Takahashi, Kenji Miyai, Development of plasma spray coated cylinders, FISITA World Automotive Congress, June 12-15, 2000, Seoul, Korea.

[4] W. Paatsch, Recent trends in surface finishing for automobile industry in Germany, Surf. Coat. Technol., 169-170 (2003) 753-757. 
[5] J.C. Walker, T.J. Kamps, R.J.K. Wood, The influence of start stop transient velocity on the friction and wear behaviour of a hyper-eutectic Al-Si automotive alloy, Wear, 306 (2013) 209-218.

[6] K. Bobzin, F. Ernst, K. Richardt, T. Schlaefer, C. Verpoort, G. Flores, Thermal spraying of cylinder bores with the plasma transferred wire arc process, Surf. Coat. Technol. 202 (2008) 4438-4443.

[7] K. Bewilogua, G. Bräuer, A. Dietz, J. Gäbler, G. Goch, B. Karpuschewski, B. Szyszka, Surface technology for automotive engineering, CIRP Annals - Manufacturing Technology, 58 (2009) 608-627.

[8] Yucong Wang, Kevin Brogan, C. Simon Tung, Wear and scuffing characteristics of composite polymer and nickel/ceramic composite coated piston skirts against aluminum and cast iron cylinder bores, Wear, 250 (2001) 706-717.

[9] Kenneth Holmberg, Peter Andersson, Ali Erdemir, Global energy consumption due to friction in passenger cars, Tribol. Int., 47 (2012) 221-234.

[10] Staffan Johansson, Per H. Nilsson, Robert Ohlsson, Cecilia Anderberg, Bengt-Göran Rose, New cylinder liner surfaces for low oil consumption, Tribol. Int., 41 (2008) 854-859.

[11] Yongjun Li, Investigation of electroless Ni-P-SiC composite coatings, Plat. Surf. Finish., 84 (1997) 77-81.

[12] Xinmin Huang, Zonggang Deng, A wear-resistant composite coating, Plat. Surf. Finish., 80 (2) (1993) 62-65.

[13] Y.S. Huang, X.T. Zeng, I. Annergren, F.M. Liu, Development of electroless NiP-PTFESiC composite coating, Surf. Coat. Technol., 167 (2003) 207-211. 
[14] I. Apachitei, F.D. Tichelaar, J. Duszczyk, L. Katgerman, The effect of heat treatment on the structure and abrasive wear resistance of autocatalytic NiP and NiP-SiC coatings, Surf. Coat. Technol., 149 (2002) 263-278.

[15] G. Straffelini, D. Colombo, A. Molinari, Surface durability of electroless Ni-P composite deposits, Wear 236 (1999) 179-188.

[16] M. Sarret, C. Müller, A. Amell, Electroless NiP micro-and nano-composite coatings, Surf. Coat. Technol., 201 (2006) 389-395.

[17] M. Ebrahimian-Hosseinabadi, K. Azari-Dorcheh, S.M. Moonir Vaghefi, Wear behavior of electroless Ni-P-B4C composite coatings, Wear 260 (2006) 123-127.

[18] M. Novák, D. Vojtěch, T. Vítů, Influence of heat treatment on tribological properties of electroless $\mathrm{Ni}-\mathrm{P}$ and $\mathrm{Ni}-\mathrm{P}-\mathrm{Al}_{2} \mathrm{O}_{3}$ coatings on $\mathrm{Al}-\mathrm{Si}$ casting alloy, Appl. Surf. Sci., 256 (2010) 2956-2960.

[19] Y.T. Wu, L. Lei, B. Shen, W.B. Hu, Investigation in electroless Ni-P-Cg(graphite)-SiC composite coating, Surf. Coat. Technol., 201 (2006) 441-445.

[20] M. Franco, W. Sha, S. Malinov, R. Rajendran, Phase composition, microstructure and microhardness of electroless nickel composite coating co-deposited with $\mathrm{SiC}$ on cast aluminium LM24 alloy substrate, Surf. Coat. Technol., 235 (2013) 755-763.

[21] D.N. Allsopp, R.I. Trezona, I.M. Hutchings, The effects of ball surface condition in the micro-scale abrasive wear test, Tribol. Lett., 5 (1998) 259-264.

[22] K.L. Rutherford, I.M. Hutchings, A micro-abrasive wear test, with particular application to coated systems, Surf. Coat. Technol., 79 (1996) 231-239. 
[23] H. Liu, H.L. Yao, Y. Liu, G.E. Thompson, Z. Liu, Crystallisation and performance characteristics of high-temperature annealed electroless Ni-W-P coatings, Cryst. Res. Technol., 49 (2014) 178-189.

[24] X.Y. Li, K.N. Tandon, Microstructural characterization of mechanically mixed layer and wear debris in sliding wear of an Al alloy and an Al based composite, Wear, 245 (2000) 148161.

[25] K.G. Keong, W. Sha, S. Malinov, Hardness evolution of electroless nickel-phosphorus deposits with thermal processing, Surf. Coat. Technol., 168 (2003) 263-274. 
Table 1. Pre-treatment processes of aluminium substrate prior to plating [20]

\begin{tabular}{lllll}
\hline Process & Chemicals & Temperature & Time & $\begin{array}{c}\text { Degree of } \\
\text { agitation }\end{array}$ \\
\hline Degreasing & $\mathrm{C}_{6} \mathrm{H} 6 \mathrm{O}$ & Room & $3-5 \mathrm{~min}$. & None \\
Alkaline cleaning & $5.75 \mathrm{~g} / \mathrm{N} \mathrm{Na}_{3} \mathrm{PO}_{4}, 5.75 \mathrm{~g} / \mathrm{l} \mathrm{Na}_{2} \mathrm{O}_{3} \mathrm{Si}$ & $60-65^{\circ} \mathrm{C}$ & $\sim 3 \mathrm{~min}$. & Mild \\
Acid neutralising & $13 \%$ vol. $\mathrm{HNO}_{3}$ & Room & $\sim 20 \mathrm{sec}$. & Mild \\
Zincating & $100 \mathrm{~g} / 1 \mathrm{ZnO}, 525 \mathrm{~g} / 1 \mathrm{NaOH}$ & Room & $\sim 20 \mathrm{sec}$ & Mild \\
\hline
\end{tabular}


Table 2. Plating process condition [20]

\begin{tabular}{ll}
\hline Parameter & Value \\
\hline $\mathrm{pH}$ & $4.8-4.9$ \\
Temperature & $88 \pm 2{ }^{\circ} \mathrm{C}$ \\
Time & $80 \mathrm{~min}$. \\
SiC concentration & $2-18 \mathrm{~g} / \mathrm{l}$ \\
Agitation & Magnetic stirrer along with sample rotator \\
\hline
\end{tabular}


Table 3. Dry sliding wear rates for various samples in as deposited and heat treated conditions

\begin{tabular}{lll}
\hline Sample & Condition & Wear rate $\left(\mathrm{m}^{2} \cdot \mathrm{N}^{-1}\right)$ \\
\hline Bare aluminium & - & $8.36 \times 10^{-12}$ \\
A & As deposited & $1.86 \times 10^{-14}$ \\
& $400^{\circ} \mathrm{C}$ & $8.11 \times 10^{-14}$ \\
B & As deposited & $3.09 \times 10^{-13}$ \\
& $400^{\circ} \mathrm{C}$ & $7.27 \times 10^{-14}$ \\
$\mathrm{C}$ & As deposited & $9.02 \times 10^{-13}$ \\
& $400^{\circ} \mathrm{C}$ & $8.91 \times 10^{-14}$ \\
$\mathrm{~F}$ & As deposited & $1.07 \times 10^{-12}$ \\
& $400^{\circ} \mathrm{C}$ & $9.37 \times 10^{-14}$ \\
\hline
\end{tabular}




\section{List of figure captions}

Fig. 1. Optical image of cross-section of the Ni-P/SiC composite coating [20] (scale bar at $100 \mu \mathrm{m})$.

Fig. 2. Wear profile for bare aluminium, electroless nickel (EN) and electroless nickel composite (ENC, $2 \mathrm{~g} / 1 \mathrm{SiC}$ ). (a) Penetration depth and (b) wear volume as functions of sliding distance.

Fig. 3. Wear scars at 400, 600, 900, 1200, 1500 and 2000 revolution for (a) bare aluminum, (b) EN and (c) ENC samples. Scale bar in the optical micrographs is $1000 \mu \mathrm{m}$.

Fig. 4. Wear tracks for (a) bare aluminium, (b) EN at smaller revolution number, (c) EN at larger revolution number, (d) ENC at smaller revolution number and (e) ENC at larger revolution number. (a, b, d) 400 revolutions; (c, e) 2000 revolutions.

Fig. 5. Wear tracks at higher magnification for (a) ENC, (b) EN and (c) bare aluminium

Fig. 6. EDX spectrum of the pressed in particle for ENC sample.

Fig. 7. Wear profile for various solution content of $\mathrm{SiC}$ of $2 \mathrm{~g} / 1$ (B), $6 \mathrm{~g} / \mathrm{l}$ (C), $10 \mathrm{~g} / \mathrm{l}$ (D), 14 g/l (E) and $18 \mathrm{~g} / \mathrm{l}(\mathrm{F})$. (a) Penetration depth and (b) wear volume.

Fig. 8. Wear scars at 400, 600, 900, 1200, 1500 and 2000 revolution for ENC samples. (a) C, (b) D, (c) E and (d) F. Scale bar in the optical micrographs is $1000 \mu \mathrm{m}$.

Fig. 9. Number of cycles (ball revolutions) required to expose the substrate. At 900 revolutions, substrate visibility can be ranked as $\mathrm{A} \approx \mathrm{F}>\mathrm{E}>\mathrm{D}$.

Fig. 10. Wear tracks post wear testing in dry sliding condition for (a) bare aluminium, (b) asdeposited sample A (c) heat treated sample A, (d) as-deposited sample B and (e) heat treated sample B. 
Fig. 11. Microhardness as a function of $\mathrm{SiC}$ solution concentration on heat treated condition. 


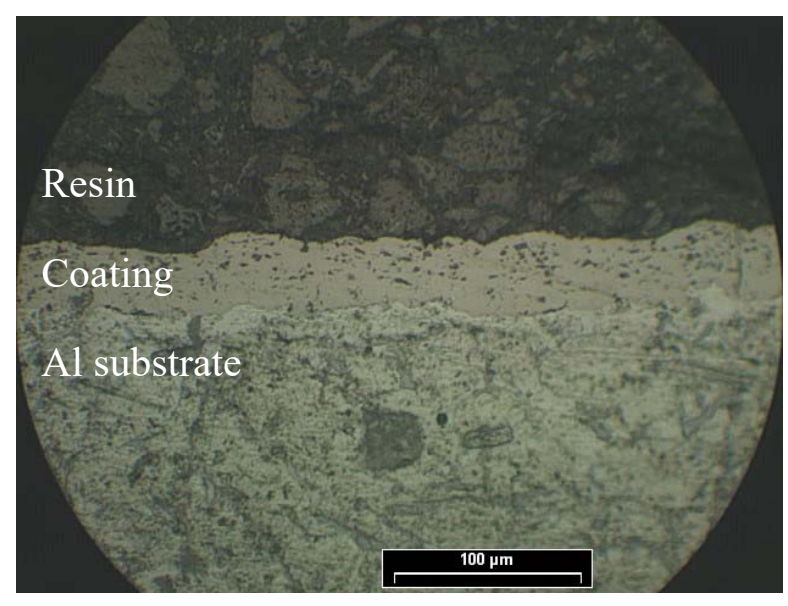

Fig. 1 


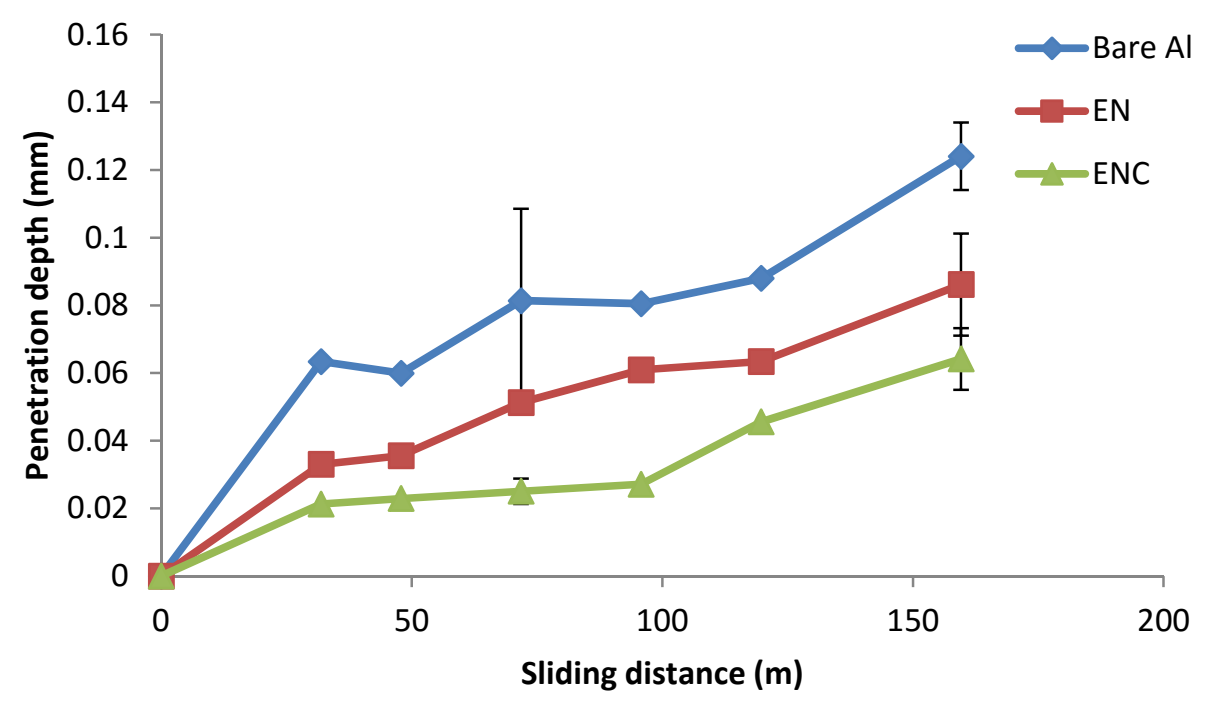

(a)

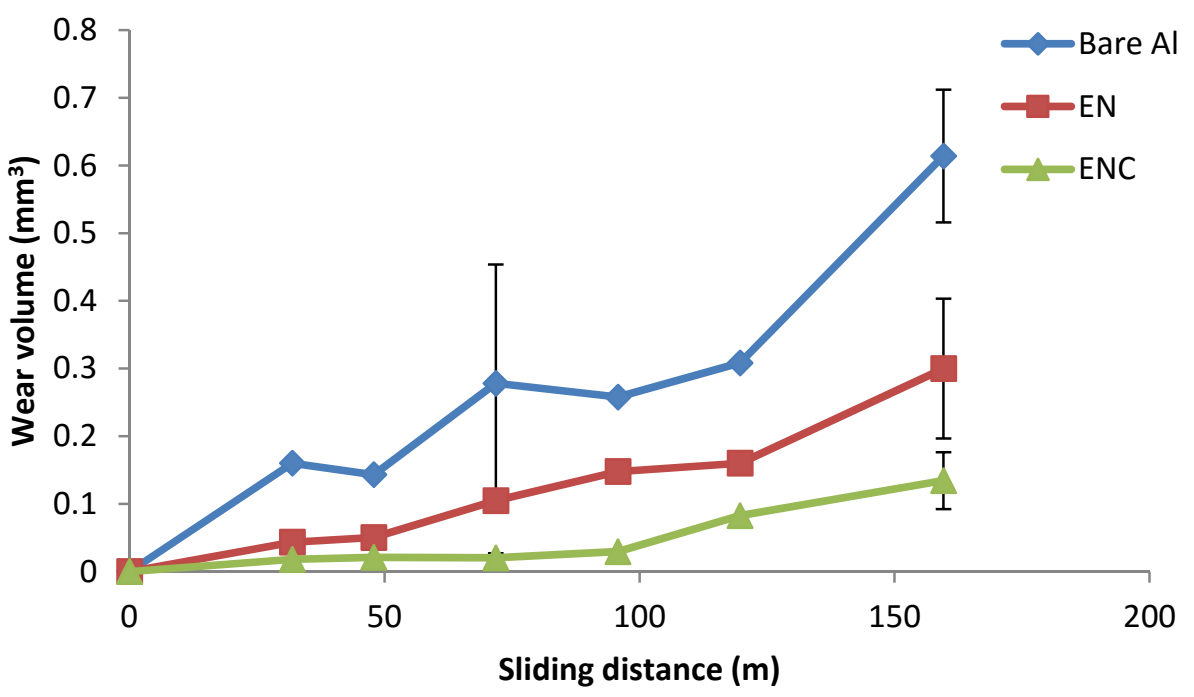

(b)

Fig. 2 

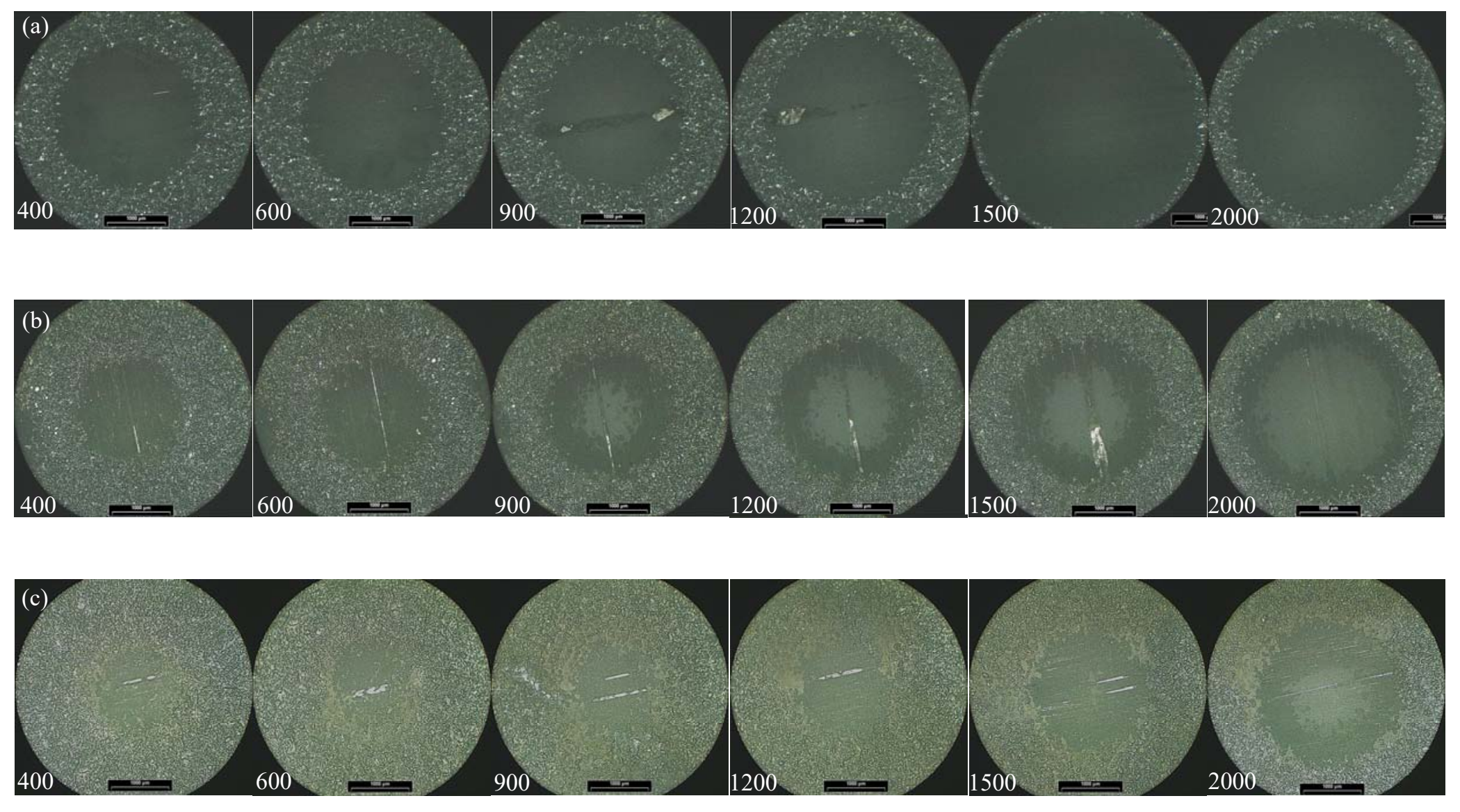

Fig. 3 

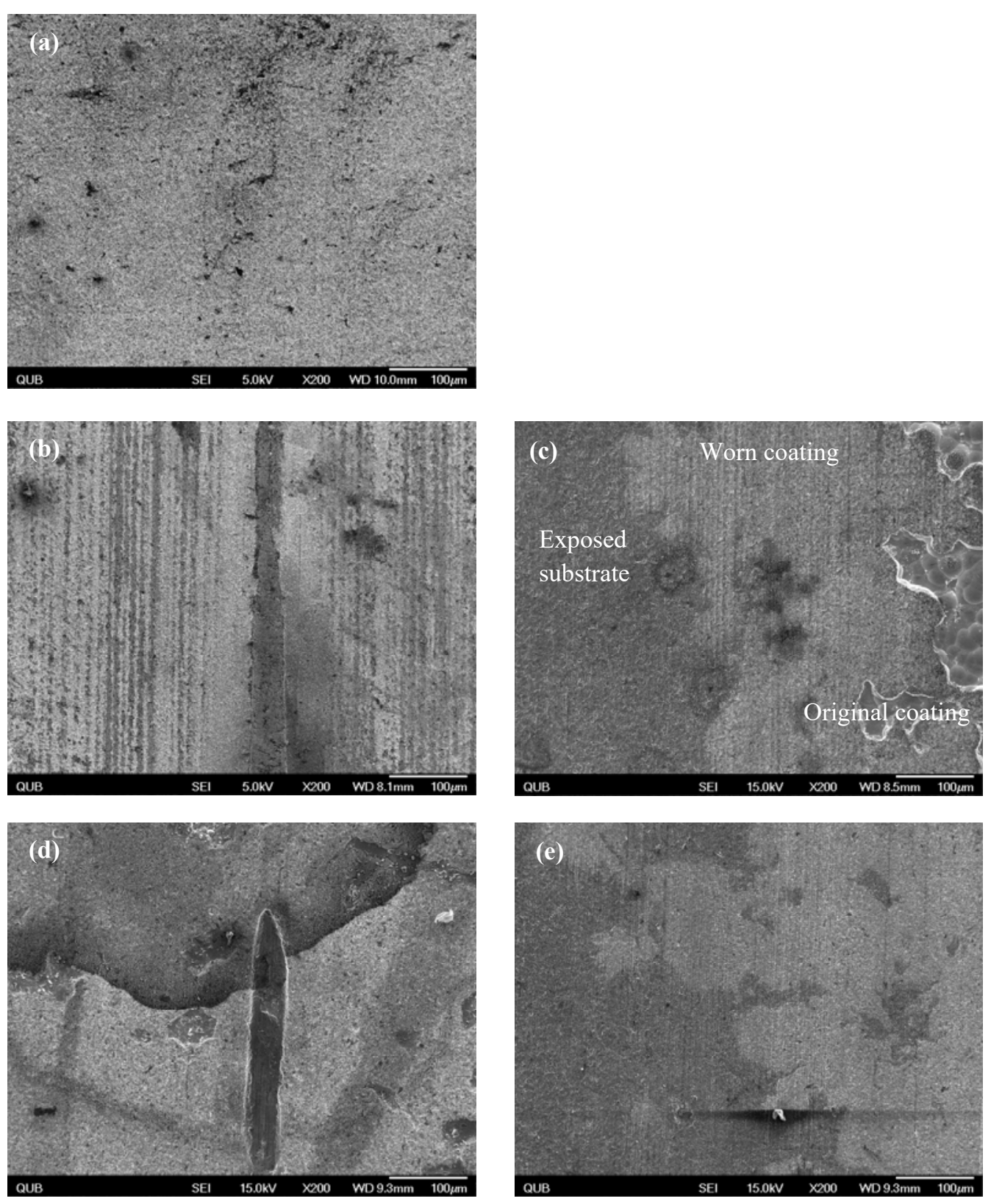

Fig. 4 

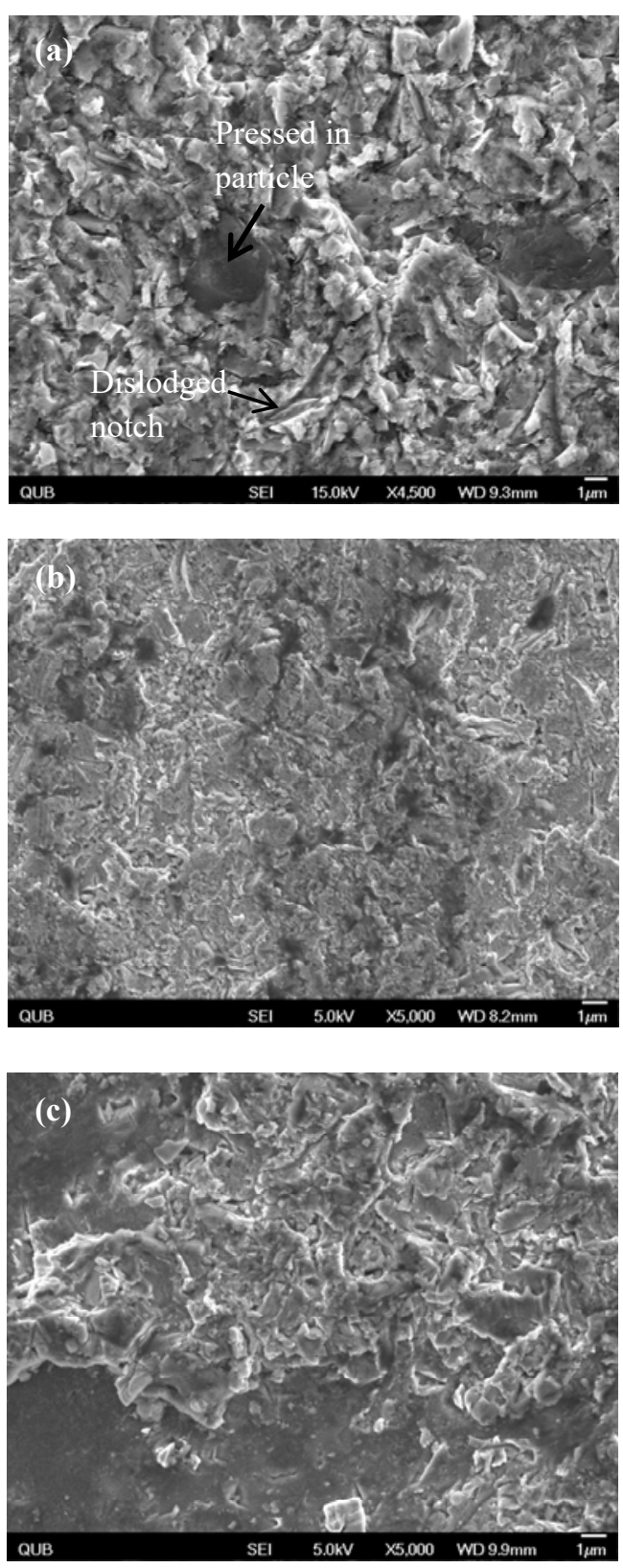

Fig. 5 

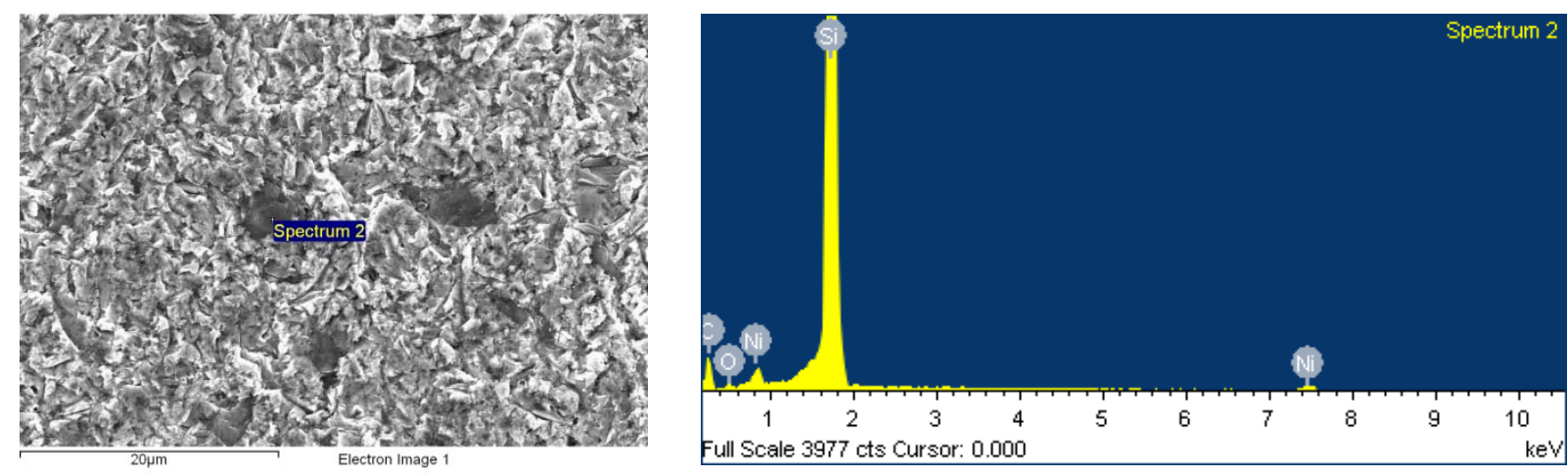

Fig. 6 


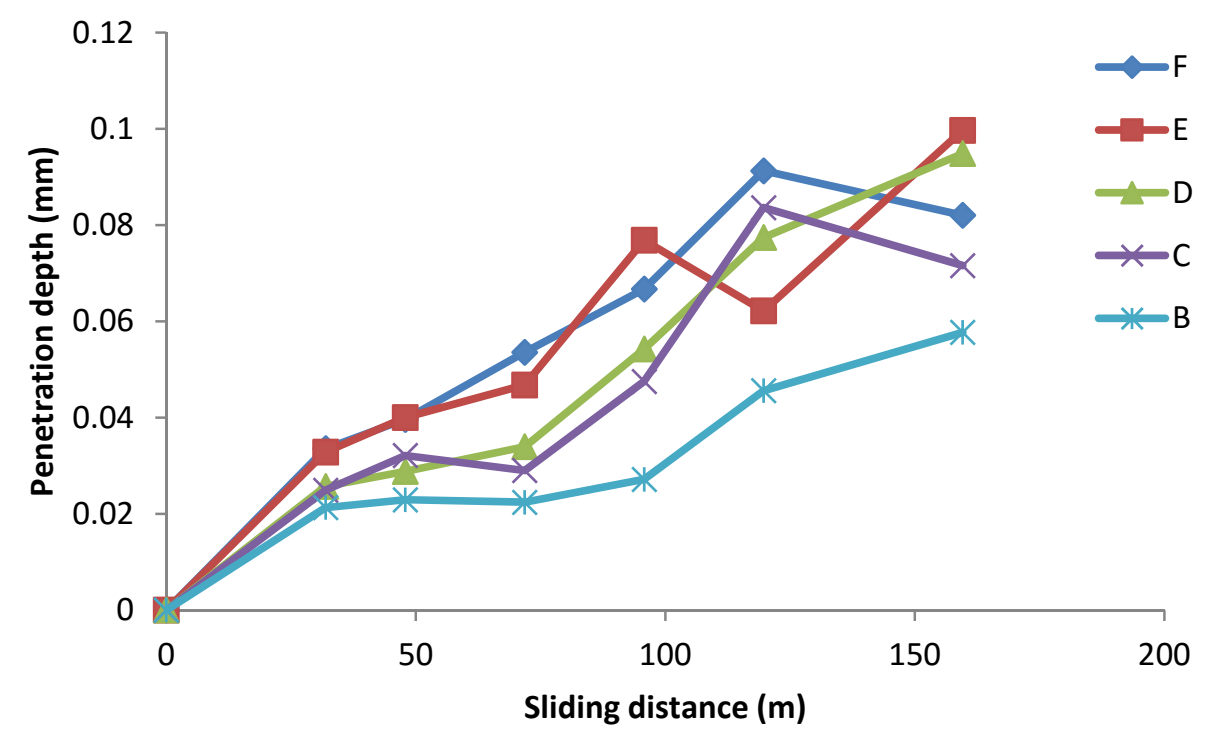

(a)

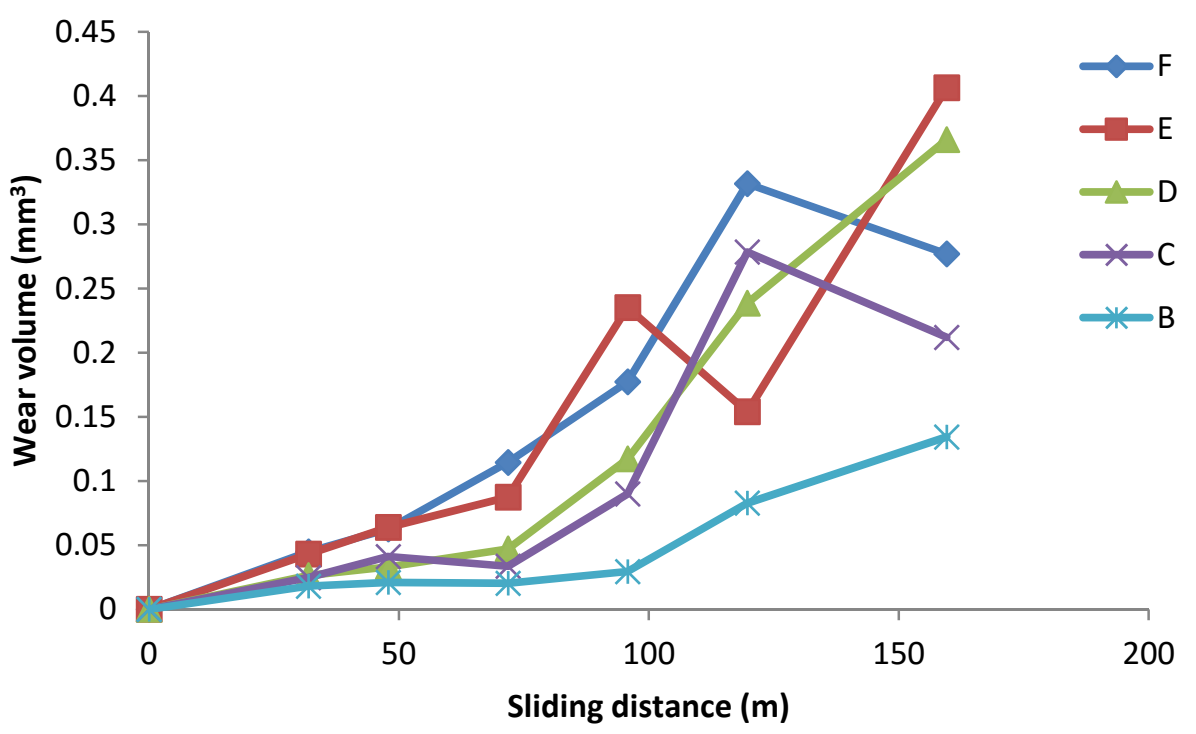

(b)

Fig. 7 

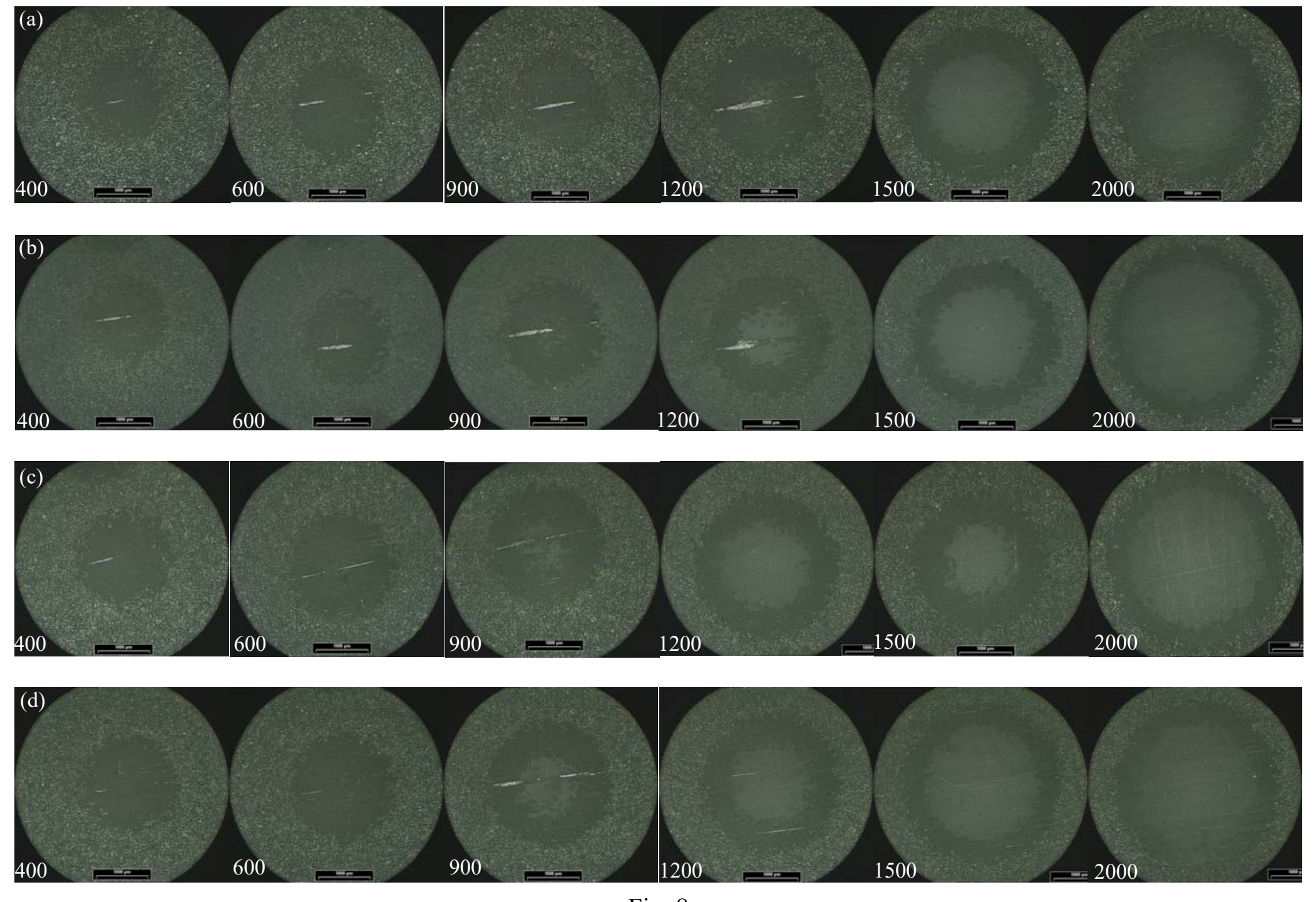

Fig. 8 


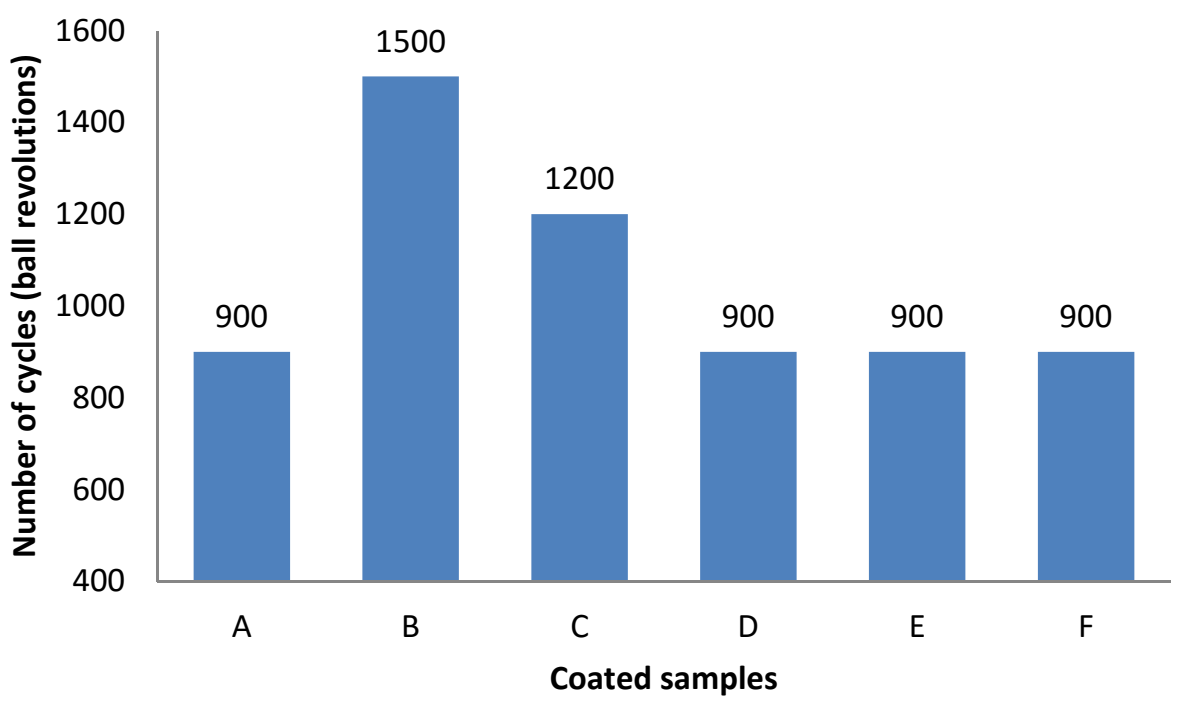

Fig. 9 

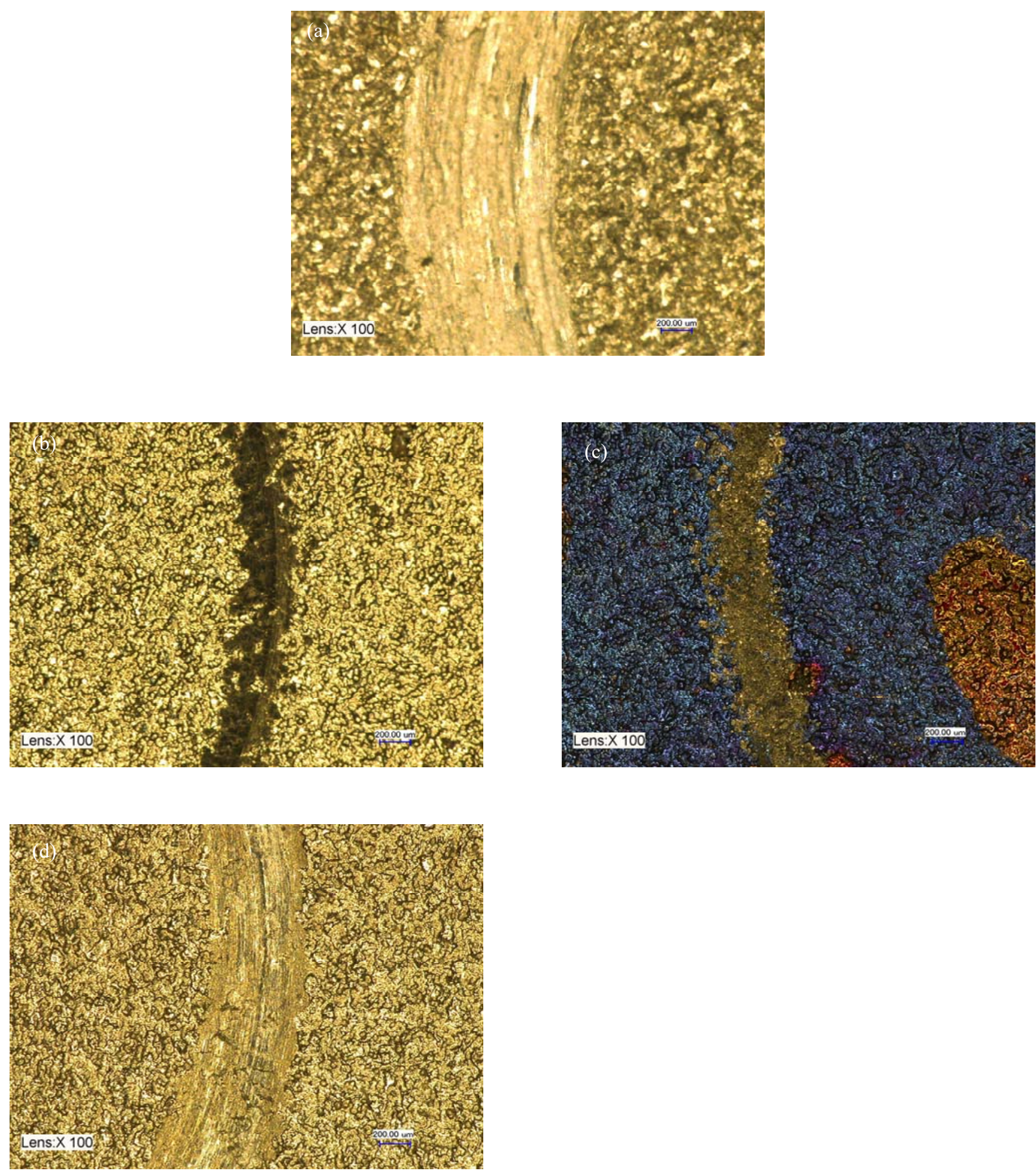

Fig. 10 


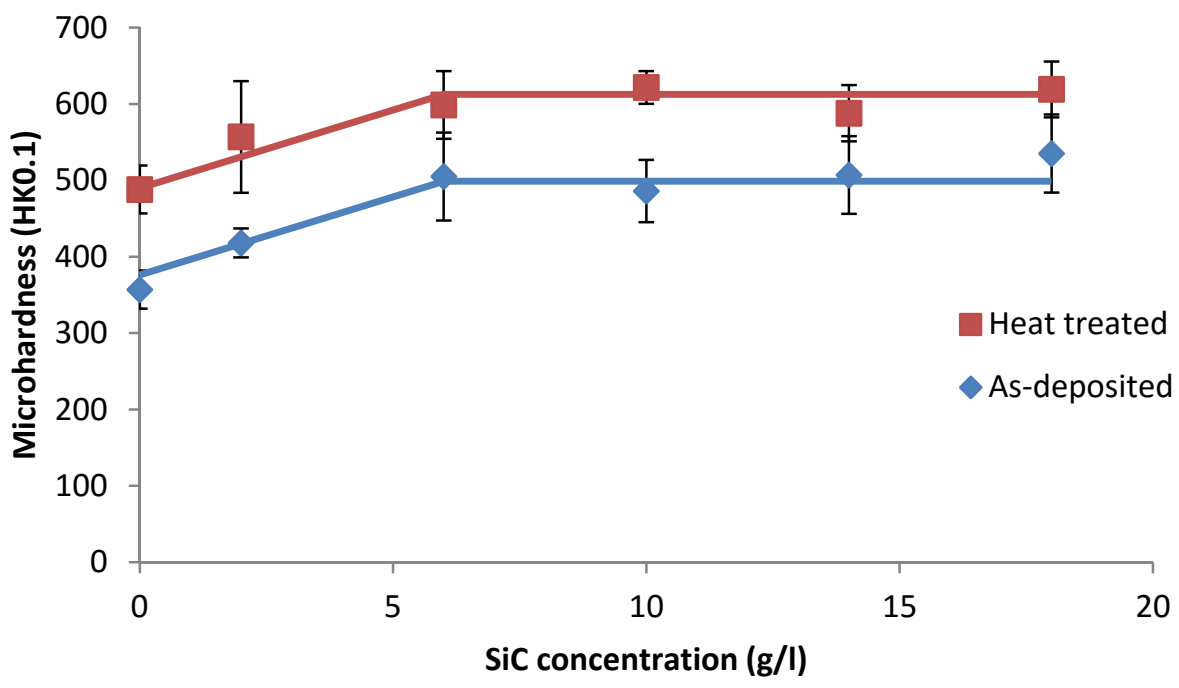

Fig. 11 